\section{Regards sur l'économie allemande}

Bulletin économique du CIRAC

$109 \mid 2013$

Varia

\title{
Tribunal constitutionnel fédéral
}

JESTAEDT Matthias, LEPSIUS Oliver, MÖLLERS Christoph, SCHÖNBERGER Christoph, Das entgrenzte Gericht. Eine kritische Bilanz nach sechzig Jahren Bundesverfassungsgericht / SCHLAICH Klaus, KORIOTH Stefan, Das Bundesverfassungsgericht. Stellung, Verfahren, Entscheidungen. Ein Studienbuch

\section{OpenEdition \\ Journals}

Édition électronique

URL : http://journals.openedition.org/rea/4578

DOI : $10.4000 /$ rea. 4578

ISSN : $1965-0787$

Éditeur

CIRAC

Édition imprimée

Date de publication : 4 juillet 2013

ISSN : 1156-8992

\section{Référence électronique}

«Tribunal constitutionnel fédéral », Regards sur l'économie allemande [En ligne], 109 | juillet 2013, mis en ligne le 19 juillet 2013, consulté le 22 septembre 2020. URL : http://journals.openedition.org/rea/ 4578 ; DOI : https://doi.org/10.4000/rea.4578

Ce document a été généré automatiquement le 22 septembre 2020.

(c) CIRAC 


\section{Tribunal constitutionnel fédéral}

JESTAEDT Matthias, LEPSIUS Oliver, MÖLLERS Christoph, SCHÖNBERGER Christoph, Das entgrenzte Gericht. Eine kritische Bilanz nach sechzig Jahren Bundesverfassungsgericht / SCHLAICH Klaus, KORIOTH Stefan, Das Bundesverfassungsgericht. Stellung, Verfahren, Entscheidungen. Ein Studienbuch

\section{RÉFÉRENCE}

JESTAEDT Matthias, LEPSIUS Oliver, MÖLLERS Christoph, SCHÖNBERGER Christoph, Das entgrenzte Gericht. Eine kritische Bilanz nach sechzig Jahren

Bundesverfassungsgericht, Suhrkamp Verlag, Berlin, 2011, 426 p.

SCHLAICH Klaus, KORIOTH Stefan, Das Bundesverfassungsgericht. Stellung,

Verfahren, Entscheidungen. Ein Studienbuch, Verlag C.H. Beck, Munich, 2012, 414 p.

1 A l'occasion $\mathrm{du} 60^{\mathrm{e}}$ anniversaire du Tribunal constitutionnel fédéral, quatre grands constitutionnalistes allemands de la jeune génération (JESTAEDT et al.) livrent ici autant de monographies indépendantes de la Cour de Karlsruhe. L'institution leur tient à cœur - ne garantit-elle pas l'ordre étatique et surtout ce principe de liberté qui le fonde? -, ce qui se lit aussi dans les critiques qu'ils formulent (un exercice classique et autorisé parmi les constitutionnalistes allemands) et plus encore leurs interrogations face à l'avenir de cette Cour dans une Europe de plus en plus intégrée. Une lecture très constructive. Pour les étudiants en droit comme tous ceux qui souhaitent mieux comprendre le statut de cette Cour, les procédures de la plainte en constitutionnalité ou la principale jurisprudence de Karlsruhe jusqu'en mars 2012, la lecture du manuel de SCHLAICH/KORIOTH ( $2^{e}$ édition augmentée) s'impose. (ib) 